\title{
THE CAUSAL ROLE OF PLASMA ALBUMIN DEFICIENCY IN EXPERIMENTAL NEPHROTIC HYPERLIPEMIA AND HYPERCHOLESTEREMIA ${ }^{1}$
}

\author{
By RAY H. ROSENMAN, MEYER FRIEDMAN, AND SANFORD O. BYERS with the \\ TECHNICAL ASSISTANCE OF MALCOLM K. SMITH
}

(From the Harold Brunn Institute, Mount Zion Hospital, San Francisco 15, Calif.)

(Submitted for publication August 29, 1955 ; accepted January 9, 1956)

Previous studies (1-8) from this laboratory have indicated that the hypercholesteremia and hyperlipemia occurring in the experimental nephrotic syndrome induced in rats by injection of anti-rat kidney serum are due primarily to some intravascular "trapping" phenomenon whereby the animal appears unable to remove either endogenously-produced or dietary-derived cholesterol and lipid from the plasma with its customary efficiency. However, since renal changes seemingly initiate the total nephrotic syndrome, it seems probable that this "trapping" of cholesterol and lipid which occurs in the plasma in this syndrome is related in some manner to such renal changes. In the present study, an attempt was made to determine the nature of this relationship. The observations herein reported suggest (a) that the hypercholesteremia and the hyperlipemia observed in the experimental nephrotic syndrome are initiated and maintained by the external renal loss of some plasma constituent, and (b) that this substance specifically is albumin.

\section{The Relationship of Nephrotic Hyperlipemia and Hypercholesteremia to Renal Damage and External Renal Excretion}

\section{Methods}

Drastic alteration in renal function was accomplished in several series of experimental and control male rats (Long-Evans strain) by 1) nephrectomy, 2) bilateral ligation of renal pedicles, 3) bilateral ureteral ligation, and 4) ureter-vena caval anastomosis.

1) Control rats. Pooled rabbit anti-rat kidney serum (AKS) was prepared as described by Heymann and Lund (9). The hypercholesteremic effect of the AKS

1 Aided by Grants from the American Heart Association, the San Francisco and Monterey County Heart Associations and from the National Institute of Arthritis and Metabolic Diseases, National Institutes of Health, Public Health Service, A-46 (C4) and Grant H-119 from the National Heart Institute, National Institutes of Health, Public Health Service. was established by injection of $1.0 \mathrm{ml}$. of it intravenously into 25 intact rats (group 1) and into 16 sham-operated (splenectomy) rats (group 2) that were bled 24 hours later for determination of plasma total cholesterol (10) and lipids (11). At the same time, 15 other normal control rats (group 3) that had been injected with $1.0 \mathrm{ml}$. of normal rabbit serum were bled in order to establish normal plasma lipid levels.

2) Nephrectomy. The second series of 45 rats was subjected to bilateral nephrectomy. Twenty-nine of these rats (group 4) were given intravenously $1.0 \mathrm{ml}$. of potent AKS immediately after the nephrectomy. The remaining 16 nephrectomized rats (group 5) served as controls, receiving $1.0 \mathrm{ml}$. of normal rabbit serum. Blood samples taken 24 hours later were analyzed for total cholesterol and those of group 4 also for total lipids. In addition, five other rats (group 6) that had been fed a protein-electrolyte-free diet (12), enabling them readily to survive for at least five days after nephrectomy, also were given $1.0 \mathrm{ml}$. of AKS immediately after nephrectomy.

3) Bilateral ligation of the renal pedicles. A third series of rats (group 7 ) was subjected to bilateral ligation of the renal pedicles by a method which obviated the possible acute effects of anesthesia and laparotomy on the animals response to a hypercholesteremic excitant. This method consisted of the application of silk ligatures applied loosely around both renal pedicles. The two ends of the ligatures were exteriorized through incisions made in the opposite lateral abdominal walls and secured to the skin surfaces. The rats then were allowed to recover for 48 hours postoperatively, at which time the exteriorized ends of the ligatures were pulled taut, thus completely interrupting the blood supply to the kidney. At the completion of the experiment, all animals were autopsied and data were used only from those animals in which complete interruption of renal circulation was observed to have occurred. Eleven rats were ligated successfully in this fashion and immediately after were injected intravenously with $1.0 \mathrm{ml}$. of AKS. Blood samples obtained 24 hours after ligation were analyzed for total cholesterol and lipids.

4) Bilateral ureteral ligation. The fourth series of 37 rats was subjected to bilateral ureteral ligation by exactly the same method described above except that a loose ligature was applied about the ureter of each kidney and then tightened 48 hours later. Twenty-four of these rats (group 8) were given intravenously $1.0 \mathrm{ml}$. of AKS immediately following ligation and the remaining 13 rats 
(group 9) served as controls, receiving $1.0 \mathrm{ml}$. of normal rabbit serum. For additional control purposes, eight rats (group 10) that had been placed four days previously upon the uremia-retarding, protein and electrolyte-free diet were similarly ligated and injected with $1.0 \mathrm{ml}$. of AKS.

All rats were sacrificed 24 hours after injection of AKS, at which time an antemortem laparotomy was performed and examination made to ensure effective ureteral ligation. In order to test the effect of the latter procedure upon the renal circulation, three rats of each group as well as five other normal rats were injected intravenously with $1.0 \mathrm{ml}$. of 0.1 per cent trypan blue and their renal pedicles clamped one minute later. The kidneys then were removed, examined grossly for their content of dye under the dissecting microscope and sections were embedded in paraffin blocks but left unstained. In addition, sections of kidneys were obtained from five other rats of each group for staining with hematoxylin and eosin, Hotchkiss' periodic acid-Schiff's reaction and the Rinehart and Abul-Haj's modified Hale stain, as described by Weinreb, Soules, and Wissler (13). At the time of sacrifice all rats were bled for determination of total cholesterol and those of group 8 also for total lipids.

5) Ureter-iena caval anastomosis. The effect of preventing external loss of urine was studied further by devising an operation which although allowing glomerular filtration, nevertheless prevented external urine loss by its diversion into the inferior vena cava.

Under ether anesthesia, the abdomen of the rat was incised, the right ureter was doubly ligated and severed about $12 \mathrm{~mm}$. from the renal pelvis. The proximal ligature, attached to a straight needle, was introduced via the right inferior lumbar vein into the inferior vena cava. The wall of the inferior vena cava opposite and slightly below the entrance of the lumbar vein was pierced with the needle and the ligature thus was pulled through this puncture until a small portion of its attached ureter also was withdrawn from the lumen of the inferior vena cava. The attachment of the ligature was then cut and the now patent distal end of the ureter was retracted back into the inferior vena cava to lie free to discharge urine therein. Simple pressure successfully prevented all bleeding from both the inferior lumbar vein and the vena cava. After this was done a loose ligature was placed around the pedicle of the left kidney and its ends brought out and secured to the skin surface as described previously. Three days later, under light ether anesthesia, the latter ligature was tightened to occlude completely the vascular pedicle of the left kidney (confirmed by subsequent autopsy).

Seven anuric rats (group 11) of this kind were obtained and injected with $1.0 \mathrm{ml}$. of AKS immediately after the ligation of the left renal pedicle. This last procedure of course produced a rat having its one functioning kidney emptying its urine into the venous circulation. For control purposes, a loose ligature was placed about only the left renal pedicle of three otherwise normal rats (group 12) and 72 hours later, the ligatures were tightened and the rats then were injected with 1.0 ml. of AKS. Blood samples obtained 24 hours after the injection of AKS were analyzed for total cholesterol. Just before sacrifice, each animal was injected with trypan blue and sections of the right kidneys of all rats were obtained and stained, as described above.

\section{Results}

\section{A. Control rats}

As shown in Table I the injection of anti-kidney serum into the control rats induced a rapid rise in plasma cholesterol, an average of $154 \mathrm{mg}$. per 100 $\mathrm{ml}$. being observed 24 hours later in the intact rats (group 1) and $126 \mathrm{mg}$. per $100 \mathrm{ml}$. in the shamoperated rats (group 2), in contrast to the average plasma cholesterol of $64 \mathrm{mg}$. per $100 \mathrm{ml}$. in the control rats injected with normal rabbit serum (group 3). A parallel rise of total lipids occurred in the animals given anti-kidney serum.

\section{B. Effect of removal of kidneys upon hypercho- lesteremic effect of $A K S$}

As Table I indicates, the removal of both kidneys prevented the hypercholesteremic effect of injected AKS. Thus the degree of hypercholesteremia ( $82 \mathrm{mg}$. per $100 \mathrm{ml}$.) in the nephrectomized rats injected with AKS (group 4) was essentially the same as that in the control nephrectomized rats given normal rabbit serum (group 5) and considerably below that found in the intact (group 1) or sham-operated control rats (group 2). The possible debility of these uremic rats moreover was not responsible for their failure to respond to the hypercholesteremic effect of AKS since similar negative results were observed in the nephrectomized rats maintained upon the uremia-retarding diet (group 6).

Functional nephrectomy, achieved by bilateral ligation of the renal vascular pedicles (group 7), likewise prevented the usual hypercholesteremic response to injection of $\mathrm{AKS}$. The bilateral nephrectomy or renal vascular pedicle ligation similarly prevented the rise of total lipids in the plasma which occurred in the control nephrotic rats (groups 1 and 2).

\section{Effect of prevention of external urine excre- tion upon hypercholesteremic effect of $A K S$}

1) Bilateral ureteral ligation. The injection of AKS into rats in whom external renal excretion 
TABLE I

Plasma lipids in rats injected with rabbit anti-kidney serum following various procedures

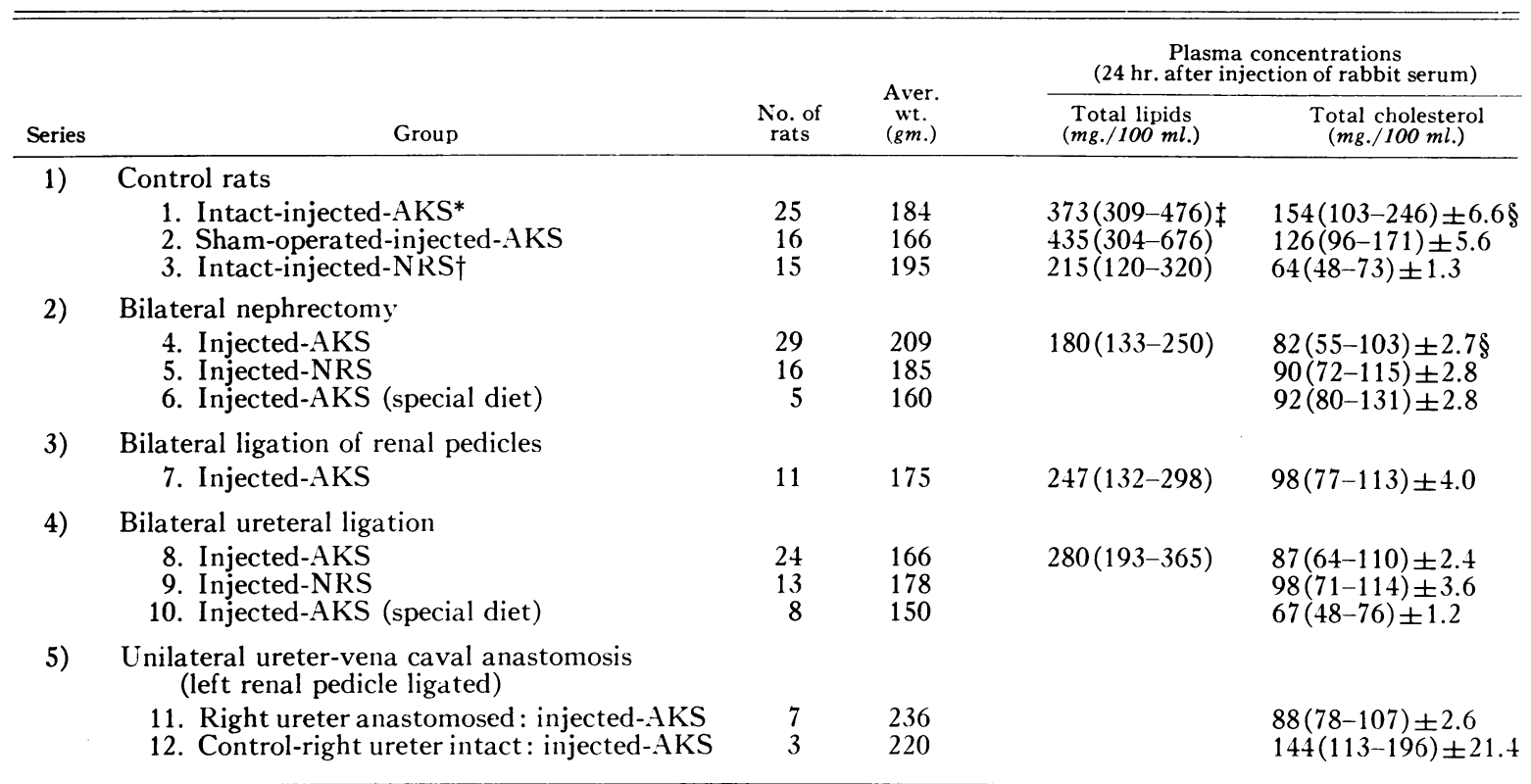

\footnotetext{
* AKS = Rabbit anti-rat kidney serum.

$\dagger$ NRS $=$ Normal rabbit serum.

$\ddagger$ Figures in parentheses refer to range of values.

$\S$ Standard error of the mean.
}

was completely abolished by bilateral ureteral ligation (group 8) did not lead to a greater degree of hypercholesteremia than that shown by the control rats, similarly operated, but injected with normal rabbit serum (group 9). Again the slight rise in cholesterol that was observed was that expected in the uremic animal (14) and again was considerably below that observed in both the intact (group 1) and sham-operated controls (group 2). Here again, as Table I indicates, even less of a rise in plasma cholesterol was observed in the ureter-ligated rats maintained on the special diet (group 10), ensuring a relatively good condition during the experimental interval.

The kidneys of the ureteral-ligated rats (groups $8,9,10$ ) that were injected with trypan blue exhibited both grossly and microscopically almost as intense staining as that observed in the kidneys of the five normal rats similarly injected. Although this suggested that the integrity of the renal circulation was preserved during the 24-hour experimental interval, it seems likely that ligation of the ureters did affect the intrarenal circulation to some extent. On the other hand, it is unlikely that the latter would in the present instance affect the development of AKS-induced renal changes since $\mathrm{AKS}$-antibodies are deposited in the kidney with great rapidity after their injection. That such is the case was suggested by comparison of the stained sections of the ureteral-ligated rats with those of the control rats (group 12) also injected with AKS 24 hours prior to study. Although neither the experimental nor the control rats exhibited the marked glomerular capillary basement membrane thickening and accumulation of acid mucopolysaccharide between the glomerular loops which are found at a later interval after injection of $\operatorname{AKS}(9,13)$, both the experimental and control rats exhibited characteristic early glomerular changes which included a neutrophilic infiltrate, some loss of the delicate markings of the capillary tufts, and some accumulation of iron-positive mucoid material between the capillary loops. Both groups of rats also exhibited typical tubular changes, especially of the proximal convoluted tubules, including granularity, paleness and decreased staining of the epithelium $(9,13)$. Necrosis of glomeruli or of tubular cells was not observed in any rats.

2) Ureter-vena caval anastomosis. Similar 
cholesterol and lipid results were obtained in the uninephrectomized rats whose remaining ureters emptied their contents back into the venous circulation (group 11). Thus, despite the fact that blood was circulating in the kidney and the glomeruli were functioning (see below), their hypercholesteremic response to AKS was the expected one from uremia alone (Compare with groups 5 and 9) and far below that observed in the control rats (group 12) which excreted urine in the usual fashion.

Similar to the findings in the kidneys of the ureteral-ligated rats, the kidneys of the rats with the ureter-vena caval anastomosis exhibited almost as intense staining with trypan blue as that observed in the kidneys of the control rats. Again early glomerular changes, similar to those described above, were observed in both groups (Figure 1). The tubular changes which included the presence of considerable amounts of excreted protein material in most of the tubules, appeared to be comparable in both the experimental and control groups, as shown in Figure 2. The finding of "proteinuria" demonstrates the altered glomerular function induced by $\mathrm{AKS}$ in both groups of rats.

\section{The Role of Plasma Albumin Deficiency in Nephrotic Hyperlipemia and Hyper- cholesteremia}

The previous studies suggested that the $e x$ ternal loss of some plasma substance(s) via the urine of the rat, following injection of AKS, was the sine qua non for the development of the hypercholesteremia and hyperlipemia of the experimental nephrotic syndrome. Since albumin is one of the plasma substances known to be excreted in great quantity in this syndrome, studies were pursued to determine if the external loss of this substance was responsible for the development of this hyperlipemia and hypercholesteremia.

\section{METHODS AND RESULTS}

\section{A. The effect of anti-kidney serum injection on plasma protein concentrations}

Methods. Twelve male, Long-Evans rats (weight: 150 to $172 \mathrm{gm}$.) were bled from the tail one week prior to injection of $1 \mathrm{ml}$. of potent $\mathrm{AKS}$ and all rats again were bled 24 hours following this injection. Each sample of blood plasma was analyzed for total cholesterol and total lipids, and for total protein and albumin concentrations (15). In addition, urine was collected from 5 of the rats during a 24-hour interval prior to and again following injection of $\mathrm{AKS}$, and analyzed for total protein content (16).

Results. The results are shown in Table II in which it can be seen that injection of AKS induced marked renal loss of protein sufficient to lower markedly plasma total protein and albumin concentrations within a 24-hour interval following injection of the immune serum. A concomitant rapid rise of total lipids and cholesterol was observed.
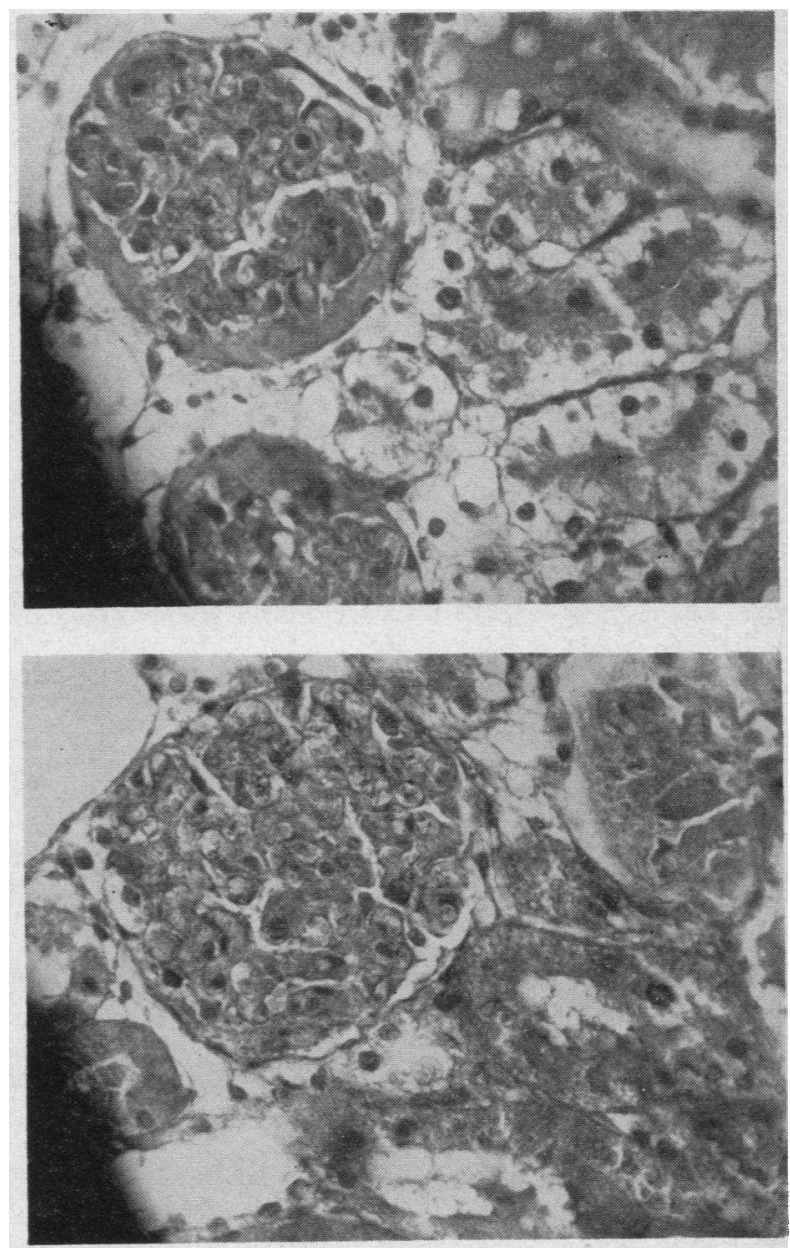

Fig. 1. (Modified Hale Stain $\times 400$.) Glomeruli of Rat with Ureter-Vena Caval Anastomosis 24 Hours after Injection of AKS, Showing Enlarged Glomeruli and Increase of Iron-Positive Material BETWEeN THE GLOMERULAR LoOPS 

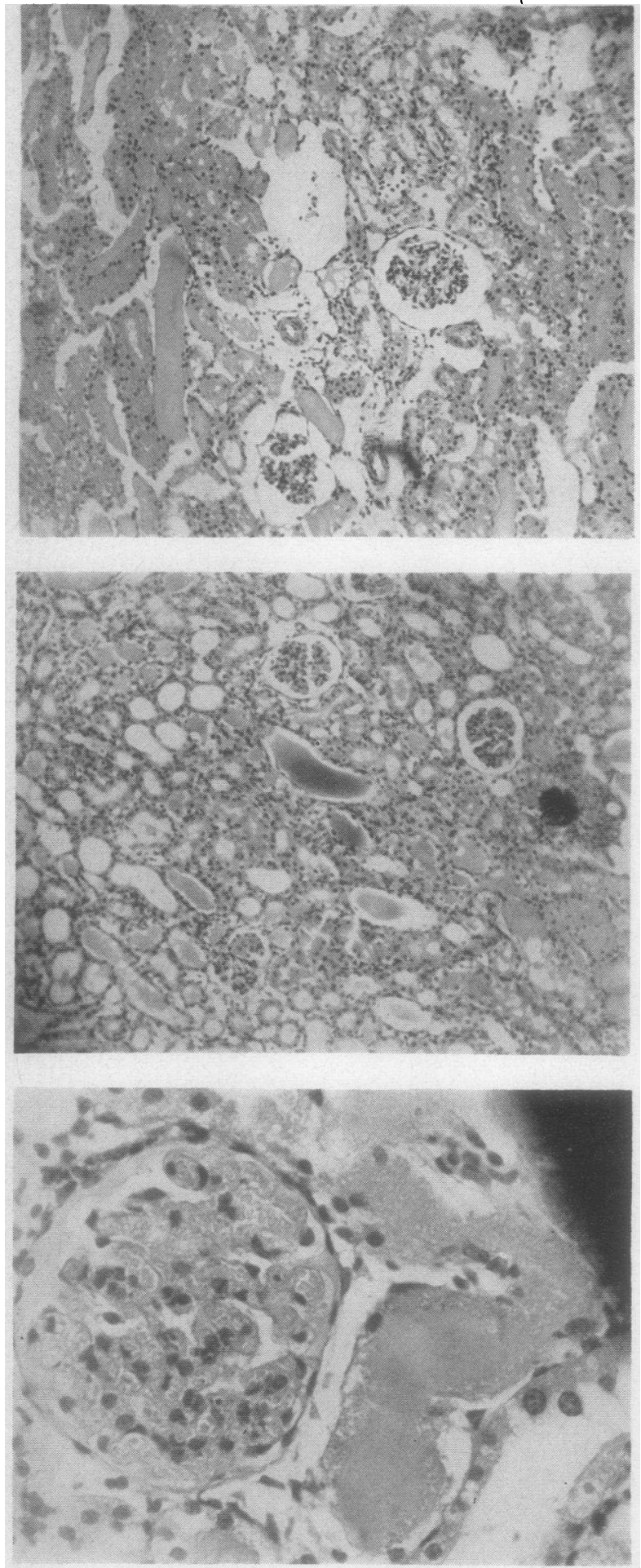

Fig. 2. (Hematoxylin and Eosin.) Top $\times 100$ Low Power View Showing Protein in Renal. Tubules of Control Rat 24 Holrs after AKS Injection. Midde $\times 100$ and Bottom $\times 400$ - Low aNd Medium Power Views of Rat with Lreter-Vena Caval Anas-
TABLE II

Plasma protein and lipid changes induced by injection of anti-kidney serum *

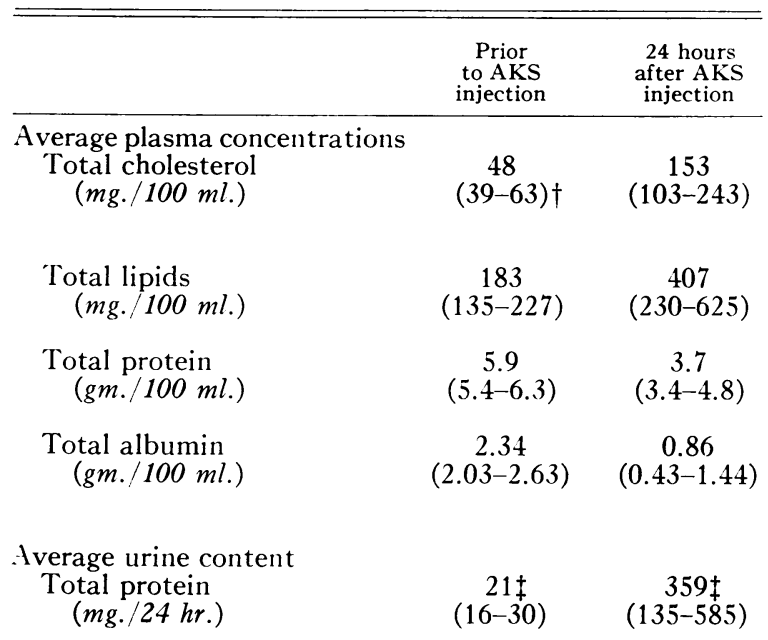

* Twelve rats.

$\dagger$ Range of values.

$\ddagger$ Five rats only.

B. The effect of albumin infusion on plasma proteins and lipids of rats injected with antikidney serum

Methods. Each of a series of 40 rats was subjected to abdominal laparotomy under ether anesthesia during which an inferior lumbar vein was cannulated with a polyethylene cannula which was exteriorized through a stab wound. Following closure of the incision the rats were individually caged in restraining units and the intravenous cannulae were connected to a special infusion apparatus designed to inject $0.3 \mathrm{ml}$. of solution per hour continuously during a 24-hour interval. Each rat then was injected with one $\mathrm{ml}$. of potent AKS. During the ensuing 24-hour interval 24 of the rats were each continuously injected with a 20 per cent aqueous solution of bovine serum albumin and the remaining 16 control animals were similarly infused, but with 0.45 per cent sodium chloride solution. The latter was used in the control rats because its retention in nephrotic plasma would probably induce some degree of hemodilution approximating that induced by infusion of albumin. Approximately $7.0 \mathrm{ml}$. of fluid thus was injected into each rat over the 24-hour period. All rats then were bled for determination of total lipids, total cholesterol and total protein and albumin. Hematocrit determinations also were made in 12 rats of each group in order to evaluate any difference in hemodilution.

In order to prevent the renal loss of the infused albumin solution, another group of rats was nephrectomized prior to the infusion. Thus a group of 10 rats was in-

tomosis 24 Hours after AKS Injection, Showing Protein in Renal Tublles, Glomerular Changes and Granclarity, Swelling and Pale Staining of Tubules 
TABLE III

Effect of albumin infusion on plasma proteins and lipids of intact and nephrectomized rats injected with anti-kidney serum

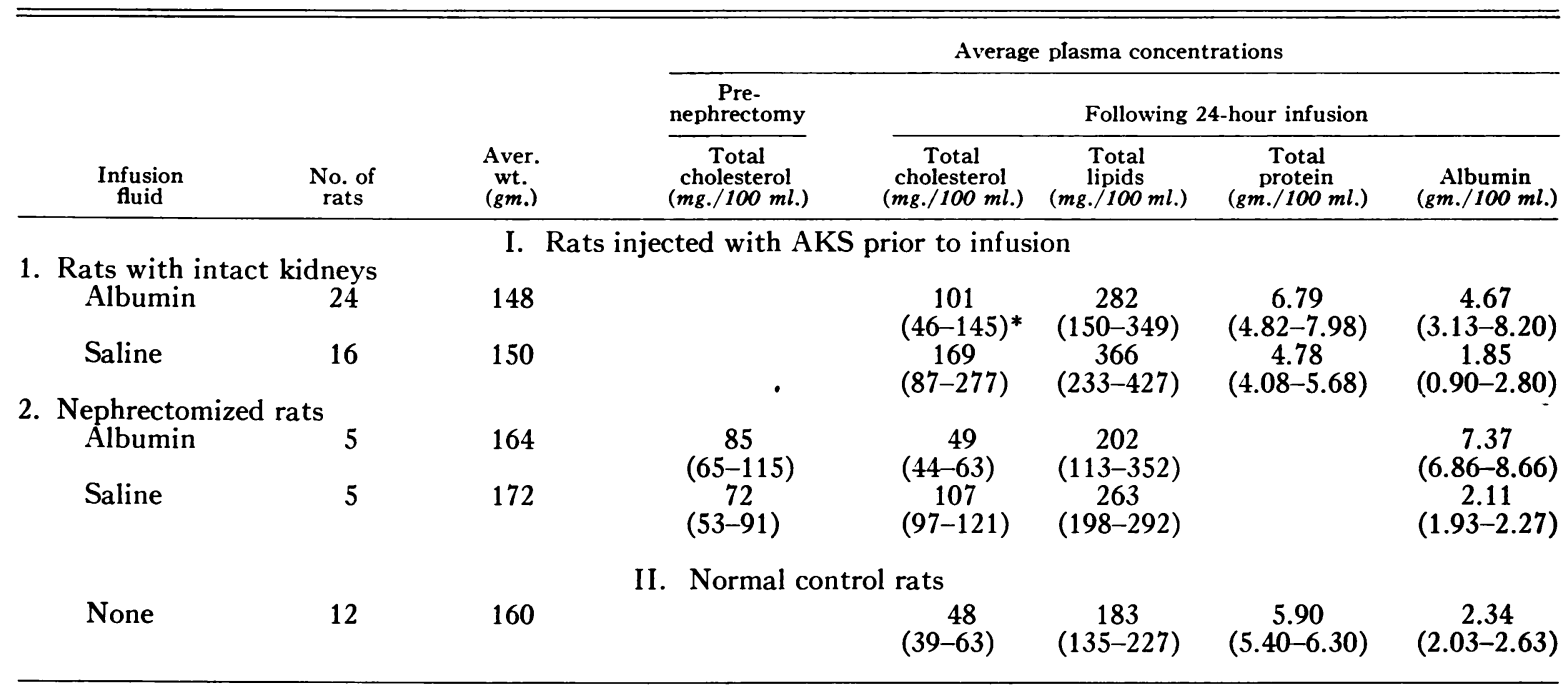

* Range of values.

jected with the AKS and subjected to bilateral nephrectomy 16 hours later. During the ensuing 24-hour postoperative interval 5 of the rats were infused with the albumin solution and 5 with saline, as described above. All rats were bled for determination of total cholesterol at the time of nephrectomy and again for total lipids; total cholesterol and albumin following the infusion interval.

Results. The results are shown in Table III. The plasma concentrations obtained from 12 normal rats (from Table II) also are included for purposes of comparison. The control rats that were infused with saline for 24 hours following injection of AKS exhibited a fall of total protein and albumin and a rise of total lipids and cholesterol in their plasma similar to that observed in the untreated nephrotic rats (see Table II). In contrast, as also shown in Table III, the infusion of albumin for 24 hours following injection of AKS prevented the usual fall of plasma total proteins and albumin in this group of rats, and their rise of plasma total lipids and cholesterol was of considerably lesser magnitude in comparison to the control animals and entirely prevented in a number of these rats. No outward evidence of toxicity was apparent in either group of rats. The observed differences were not found due to significantly different states of hemodilution since the average hematocrit in 12 rats infused with albumin solution was 42 (Range: 35 to 50 ) while in the control rats infused with saline the average hematocrit was 50 (Range : 44 to 56).

At the time of nephrectomy, performed 16 hours after injection of the AKS, only a moderate rise of the average plasma cholesterol had occurred. established nephrotic hypercholesteremia

\begin{tabular}{|c|c|c|c|c|c|}
\hline \multirow[b]{3}{*}{$\begin{array}{l}\text { Infusion } \\
\text { fluid }\end{array}$} & \multirow[b]{3}{*}{$\begin{array}{c}\text { No. of } \\
\text { rats }\end{array}$} & \multirow[b]{3}{*}{$\begin{array}{l}\text { Aver. } \\
\text { wt. } \\
(\mathrm{gm} .)\end{array}$} & \multicolumn{3}{|c|}{ Average plasma concentrations } \\
\hline & & & \multirow{2}{*}{$\begin{array}{c}\begin{array}{c}\text { Prior to } \\
\text { infusion }\end{array} \\
\begin{array}{c}\text { Total } \\
\text { cholesterol } \\
(\mathrm{mg} . / 100 \mathrm{ml} .)\end{array}\end{array}$} & \multicolumn{2}{|c|}{ Following 24-hour infusion } \\
\hline & & & & $\begin{array}{c}\text { Total } \\
\text { cholesterol } \\
(\mathrm{mg} . / 100 \mathrm{ml} .)\end{array}$ & $\begin{array}{c}\text { Total } \\
\text { albumin } \\
(\mathrm{gm} . / 100 \mathrm{ml} .)\end{array}$ \\
\hline Albumin & 8 & 152 & 239 & 159 & 3.38 \\
\hline Saline & 6 & 148 & $\begin{array}{c}(124-325)^{*} \\
220 \\
(117-325)\end{array}$ & $\begin{array}{c}(54-286) \\
226 \\
(135-336)\end{array}$ & $\begin{array}{c}(2.27-4.35) \\
1.37 \\
(1.05-2.77)\end{array}$ \\
\hline
\end{tabular}

* Range of values. 
TABLE V

Changes in plasma lipids and albumin following completion of albumin infusion in rats injected with $A K S$

\begin{tabular}{|c|c|c|c|c|c|c|c|}
\hline \multirow[b]{4}{*}{$\begin{array}{l}\text { Type of } \\
\text { infusion }\end{array}$} & \multirow[b]{4}{*}{$\begin{array}{c}\text { No. of } \\
\text { rats }\end{array}$} & \multirow[b]{4}{*}{$\begin{array}{l}\text { Aver. } \\
\text { wt. } \\
\text { (gm.) }\end{array}$} & \multicolumn{5}{|c|}{ Average plasma concentrations } \\
\hline & & & \multirow{3}{*}{ 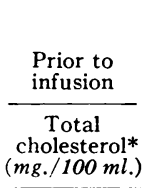 } & \multicolumn{4}{|c|}{ Following infusion } \\
\hline & & & & \multirow{2}{*}{ 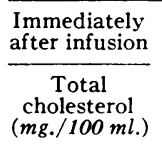 } & \multicolumn{3}{|c|}{24 hours after infusion terminated } \\
\hline & & & & & $\begin{array}{c}\text { Total } \\
\text { cholesterol } \\
(m g . / 100 \mathrm{ml} .)\end{array}$ & $\begin{array}{c}\text { Total } \\
\text { lipids } \\
(\mathrm{mg} .1100 \mathrm{ml} .)\end{array}$ & $\begin{array}{c}\text { Total } \\
\text { albumin } \\
(\mathrm{gmm} / 100 \mathrm{ml} .)\end{array}$ \\
\hline Albumin & 5 & 172 & $\begin{array}{c}97 \\
(41-133)+\end{array}$ & $\begin{array}{c}90 \\
(51-120)\end{array}$ & 194 & $\begin{array}{c}823 \\
(194-1360)\end{array}$ & $\begin{array}{c}1.58 \\
(1.03-29\end{array}$ \\
\hline Saline & 5 & 168 & $\begin{array}{c}99 \\
(44-188)\end{array}$ & $\begin{array}{c}167 \\
(87-277)\end{array}$ & $\begin{array}{c}221 \\
(109-336)\end{array}$ & $\begin{array}{c}920 \\
(375-1,970)\end{array}$ & $\begin{array}{c}1.00 \\
(0.74-1.57)\end{array}$ \\
\hline
\end{tabular}

* Sixteen hours after AKS injection.

$\dagger$ Range of values.

Removal of the kidneys prevented further renal loss of albumin and, as shown in Table III, albumin infusion into the nephrectomized rats previously injected with AKS was associated with a fall of their plasma cholesterol to normal levels. The concentration of plasma lipids and cholesterol in the saline-injected group was also of lesser magnitude than in the saline-treated control rats with intact kidneys, the further slight rise of cholesterol following nephrectomy in these rats being ascribed to the effect of nephrectomy per se on the blood lipids (see Table I).

\section{The effect of albumin administration on plasma albumin and lipids of rats with previously es- tablished nephrosis}

Methods. Fourteen rats were each injected with one $\mathrm{ml}$. of potent AKS and one week later all rats were bled for determination of total cholesterol. Each rat was subjected to cannulation of the lumbar vein as described above. During the ensuing 24-hour interval eight rats were infused with $7.0 \mathrm{ml}$. of 20 per cent solution of bovine albumin and the remaining six control animals were each injected with $7.0 \mathrm{ml}$. of 0.45 per cent saline solution. At the end of the 24-hour infusion interval all rats were bled for determination of total cholesterol and albumin concentrations.

Results. In Table IV it can be seen that the control nephrotic rats, following the infusion of saline solution, exhibited no significant change in their plasma cholesterol levels. However, as observed in the previous experiment, the infusion of albumin again considerably raised the plasma albumin levels above those of the controls. These rats, as might now be expected, exhibited a fall in their plasma cholesterol levels, in contrast to the control rats.
D. The effect of stopping the infusion of albumin on the plasma lipids and cholesterol of rats injected with anti-kidney serum

Methods. Ten rats were each injected with $1.0 \mathrm{ml}$. of potent AKS and bled for determination of total cholesterol 16 hours later. As described above, each rat then was subjected to cannulation of a lumbar vein and in the ensuing 24-hour interval, 5 of the rats were continuously infused with $7.0 \mathrm{ml}$. of the serum bovine solution (20 per cent) and 5 of the rats, serving as controls, were infused with 0.45 per cent saline solution. All animals then were bled for determination of total cholesterol. The infusion then was discontinued and 24 hours later both the experimental and control rats were bled for determination of total lipids, total cholesterol and albumin.

Results. The results of the analyses are shown in Table $\mathrm{V}$ in which it can be seen that 16 hours after injection of AKS only a moderate hypercholesteremia had developed in both the experimental and control rats. The average plasma cholesterol of the control rats receiving the saline infusion however, continued to rise progressively not only during the infusion interval but 24 hours after the latter's discontinuance, at which time marked hyperlipemia and hypoalbuminemia also were observed. In contrast, continuous infusion of the albumin solution into the experimental rats prevented further rise of the plasma cholesterol during the period of infusion. However, 24 hours after the infusion had been discontinued, their plasma cholesterol and lipids rose to levels comparable to those observed in the control rats. At this time too, the plasma albumin content of both groups of rats was approximately the same. By comparison with the data in Tables III and IV it can be seen that there was a rapid disappearance of the infused albumin $(17,18)$. This suggests of 
course that, with the discontinuance of the albumin infusion, the experimental rats lost their artificially maintained elevated plasma albumin levels and in so doing, again became markedly hypercholesteremic and hyperlipemic.

\section{DISCUSSION}

Previously it was found that the hyperlipemia and hypercholesteremia of the nephrotic rat are of endogenous origin (2) and cannot be ascribed to any increased intestinal absorption (3) or decreased intestinal excretion (5). Moreover it was shown that the hepatic synthesis of cholesterol, the major source of the plasma cholesterol (19) is not increased in the nephrotic rat (4). Furthermore, it was found that the rise of lipids and cholesterol in the nephrotic rat is an isolated accumulation confined to the plasma, apparently consequent to a failure in the usual transfer and egress of cholesterol and other lipids from the plasma into the liver (6). In other words the isolated rise of plasma lipids appears due to a "trapping" phenomenon in the plasma (8), an effect which is probably augmented by the rise of cholate which also occurs in the nephrotic state (1). There is an associated endogenous chylomicronemia (7).

The presently reported experiments indicate that this "trapping" phenomenon is intimately related to and indeed initiated by a primary renal derangement. This is understandable because apparently the total experimental nephrotic syndrome stems from some initial reaction between renal tissue and the anti-kidney serum. The failure of nephrotic hypercholesteremia and hyperlipemia to appear in the absence of renal tissue was demonstrated previously by Heymann and Hackel (20). The present observations confirm their finding that viable renal tissue must be present for the initial renal reaction leading to the development of nephrotic hypercholesteremia and hyperlipemia in the experimental animal. The data further indicate, however, that the rise of plasma lipids will not occur, despite the demonstrated occurrence of the AKS-induced renal damage, unless an $e x$ ternal loss of some plasma constituent occurs in the urine, either as a result of or in association with this renal damage. This was shown by the finding that if the external loss of urine by the kidney was prevented by ureteral ligation or ureter-vena caval anastomosis, the development of nephrotic hypercholesteremia and hyperlipemia was prevented despite the occurrence of the typical lesions both in the glomerulus and tubules.

These observations therefore indicate that the rise of plasma lipids is initiated by the external renal loss of some plasma constituent via the urine. The present observations further suggest that this particular substance lost in the urine is plasma albumin, because when sufficient albumin was given to AKS-injected rats to overcome the plasma deficit otherwise resulting from its rapid renal loss (17), hyperlipemia and hypercholesteremia either were prevented or markedly inhibited during the induction stage as well as ameliorated in the previously established nephrotic state. Furthermore, the subsequent rapid disappearance of the infused albumin from the circulation (17, 18) of some of these rats was associated with a concomitant rapid rise of serum lipids and cholesterol of similar magnitude to that of the control nephrotic rats.

The induced rise of plasma albumin to normal or greater levels was not associated with a fall of the plasma lipids and cholesterol entirely to normal concentrations in all rats. This may be due to the fact that bovine serum albumin, because of its ready availability, was used in these studies instead of concentrated rat serum albumin, and the physico-chemical state of such albumin is somewhat altered during the procedures used in its preparation and purification. Moreover, the egress of excess lipid from the circulation is a gradual process even in the normal animal (21), and a similar situation would obtain in the nephrotic rat despite alleviation of the metabolic block which otherwise prevents the usual egress of cholesterol and other lipids from the plasma in such rats.

Various observers (22-31) have failed to find a close inverse correlation between lowered plasma protein and elevated lipid content in both clinical and experimental nephrosis. However, determinations of total protein, rather than of the albumin fraction, generally were done and since globulins rise in nephrotic plasma (32), conclusions based upon such determinations may not be valid. Indeed, when the correlation between ele- 
vated plasma lipids and lowered albumin rather than total protein has been studied, a much closer inverse relationship has been found in nephrotic patients $(33,34)$. A rise of plasma albumin, when induced by ACTH in nephrotic patients, is associated with a fall of plasma cholesterol regardless of the pattern of diuresis (35), and during clinical remissions. in nephrotic patients it has been observed that shifts of plasma cholesterol and albumin occur together, both reaching normal levels nearly simultaneously (34). Moreover, no significant hyperlipemia and hypercholesteremia are observed as a consequence of the renal damage occurring in glomerular nephritis $(25,26)$ or in the many diverse states in which the nephrotic state may occur (35) unless there is excessive urine protein loss $(26,36,37)$. In other words, the common denominator for "nephrotic" lipemia does not appear to be the renal lesion per $s e$ but the external renal loss of plasma albumin sufficient to induce hypoalbuminemia. This is consonant with the finding that a similar inverse plasma lipid-protein relationship has been observed clinically and experimentally in such other non-nephritic conditions in which plasma albumin is lowered as repeated blood loss in animals (38-40) and man (41), in patients with severe proteinuria due to constrictive pericarditis and renal thrombosis (37), in rats treated with DCA (42) or concomitantly with renin and adrenocortical steroids (42), in dogs fed low protein diets (43), and in animals made proteinuric by a nephrotoxin such as uranium (44).

Although the present data suggest that hypoalbuminemia initiates and maintains the processes both of hyperlipemia and hypercholesteremia, the sequential mechanism remains unclear. However, albumin is an essential component of lipemiaclearing processes (45) and the hydrolysis of plasma fats is markedly inhibited by the absence of adequate plasma albumin with available binding sites for fatty acids (45). The accumulation of plasma lipids may result from an inadequate supply of albumin for transport of these lipid breakdown products (46) from the plasma into the tissues and may in turn be responsible for the hypercholesteremia. In support of this last hypothesis is the recent finding in this laboratory (47) that an experimentally induced hyperlipemia quickly produces a hypercholesteremia. It thus is quite possible that the hypercholesteremia observed in the nephrotic state does not represent an initial or intrinsic error in cholesterol metabolism but a passively induced phenomenon secondary to the "heaping up" of lipids in the plasma consequent to the deficiency of plasma albumin. It is of considerable interest that Albrink, Man, and Peters (48) recently proposed the possibility of such a mechanism following their discovery of the preferential solubility of cholesterol in the neutral fat of plasma. It is also of interest that some years ago Addis (49), in considering the mechanism of nephrotic lipemia, hypothesized that, "In some such manner we can ... . see the milky plasma as the result of an absence of plasma protein molecules that have ... transport function. Then the fatty acid molecules . . . would be left free in the water of the plasma and they would coalesce into the little fat globules that make the creamy emulsion we see." . . . "The lipemia may be a result of the decrease or absence of certain protein elements between whose layers fatty acid molecules usually lie recessed. We may suppose these proteins carry the fat in molecular dispersion and obviate their coalescence into droplets. $\mathrm{Li}$ pemia may thus be a manifestation of an inadequate transport system analogous to a traffic jam on the road. ..."

\section{SUMMARY}

The prevention of external loss of urine in rats, either by ureteral ligation or by ureteral-vena caval anastomosis invariably prevented the hypercholesteremia and hyperlipemia otherwise observed following injection of rabbit anti-rat kidney serum. This suggests that the cholesterol and lipid abnormality observed in experimentally induced nephrosis is secondary to the external loss of one or more plasma substance.

Prevention or correction of the plasma albumin deficiency in the nephrotic rat was observed to inhibit markedly the hypercholesteremia and hyperlipemia otherwise occurring in association with the decreased plasma albumin induced by injection of anti-kidney serum.

It is suggested that the hyperlipemia and hypercholesteremia occurring in experimentally induced nephrosis result from the deficiency of circulating plasma albumin occurring in this disorder. 


\section{ACKNOWLEDGMENT}

We wish to express our thanks to Dr. Sanford L. Steelman of the Armour Laboratories for the bovine serum albumin which was used in these studies.

\section{REFERENCES}

1. Rosenman, R. H., Friedman, M., and Byers, S. O., Observations concerning the cholate: Cholesterol relationship in clinical and experimental nephrosis. J. Clin. Invest., 1953, 32, 121.

2. Friedman, M., Rosenman, R. H., and Byers, S. O., The role of exogenous lipids in the hyperlipemia and hypercholesteremia of nephrotic rats. J. Clin. Invest., 1954, 33, 1103.

3. Rosenman, R. H., Friedman, M., and Byers, S. O., Intestinal absorption of cholesterol by the nephrotic rat. Circ. Res., 1954, 2, 256.

4. Byers, S. O., Friedman, M., and Rosenman, R. H., Hepatic synthesis of cholesterol in nephrotic rats. Am. J. Physiol., 1954, 178, 327.

5. Byers, S. O., Rosenman, R. H., and Friedman, M., The intestinal excretion of cholesterol and total lipids by the nephrotic rat. Am. J. Physiol., 1955, 182, 73.

6. Rosenman, R. H., Friedman, M., and Byers, S. O., The distribution of cholesterol and total lipids in the nephrotic rat. J. Clin. Invest., 1955, 34, 700.

7. Byers, S. O., and Friedman, M., Observations concerning the production and excretion of cholesterol in mammals. XIII. Role of chylomicra in transport of cholesterol and lipid. Am. J. Physiol., 1954, 179, 79.

8. Friedman, M., Rosenman, R. H., and Byers, S. O., Deranged cholesterol metabolism and its possible relationship to atherosclerosis: A review. J. Gerontol., 1955, 10, 60.

9. Heymann, W., and Lund, H. Z., Nephrotic syndrome in rats. Pediatrics, 1951, 7, 691.

10. Zlatkis, A., Zak, B., and Boyle, A. J., A new method for the direct determination of serum cholesterol. J. Lab. \& Clin. Med., 1953, 41, 486.

11. Bragdon, J. H., Colorimetric determination of blood lipides. J. Biol. Chem., 1951, 190, 513.

12. Ledingham, J. M., The influence of the adrenal on the water and electrolyte disturbances following nephrectomy and its relation of renoprival hypertension. Clin. Sc., 1954, 13, 535.

13. Weinreb, M. S., Soules, K. H., and Wissler, R. W., Quantitative studies of acute nephrotoxic nephritis in rats. Am. J. Path., 1954, 30, 311.

14. Svanborg, A., Studies on renal hyperlipemia. Acta med. Scandinav., 1951, vol. 141, Suppl. 264.

15. Wolfson, W. Q., Cohn, C., Calvary, E., and Ichiba, F., Studies in serum proteins. V. A rapid procedure for the estimation of total protein, true albumin, total globulin, alpha globulin, beta globulin, and gamma globulin in $1.0 \mathrm{ml}$. of serum. Am. J. Clin. Path., 1948, 18, 723.
16. Kolmer, J. A., and Boener, F., Approved Laboratory Technique. 2nd Edition. New York, Appleton Century, 1938.

17. Drabkin, D. L., and Marsh, J. B., Metabolic channeling in experimental nephrosis: I. Protein and carbohydrate metabolism. J. Biol. Chem., 1955, 212, 623.

18. Luetscher, J. A., Jr., Hall, A. D., and Kremer, V. L., Treatment of nephrosis with concentrated human serum albumin. I. Effects on the proteins of body fluids. J. Clin. Invest., 1949, 28, 700.

19. Friedman, M., Byers, S. O., and Michaelis, F., Production and excretion of cholesterol in mammals. IV. Role of liver in restoration of plasma cholesterol after experimentally induced hypocholesteremia. Am. J. Physiol., 1951, 164, 789.

20. Heymann, W., and Hackel, D. B., Role of kidney in pathogenesis of experimental nephrotic hyperlipemia in rats. Proc. Soc. Exper. Biol. \& Med., 1955, 89, 329.

21. Friedman, M., Byers, S. O., and Gunning, B., Observations concerning production and excretion of cholesterol in mammals. VIII. Fate of injected cholesterol in the animal body. Am. J. Physiol., 1953, 172, 309.

22. Daniels, W. B., Plasma-lipoids in renal disease. Brit. J. Exper. Path., 1925, 6, 283.

23. Lichtenstein, L., and Epstein, E. Z., The blood lipoids in nephrosis and chronic nephritis with edema. Arch. Int. Med., 1931, 47, 122.

24. Calvin, J. K., and Goldberg, A. H., Cholesterol and edema. Their relationship in a group of children presenting the nephrotic syndrome. Am. J. Dis., Child., 1931, 41, 1066.

25. Page, I. H., Kirk, E., and Van Slyke, D. D., Plasma lipids in chronic hemorrhagic nephritis. J. Clin. Invest., 1936, 15, 101.

26. Peters, J. P., and Man, E. B., The interrelations of serum lipids in patients with diseases of the kidneys. J. Clin. Invest., 1943, 22, 721.

27. Farr, L. E., Smadel, J. E., and Holden, R. F., Jr., Observations on occurrence of lipemia in rats with nephrotoxic nephritis. Proc. Soc. Exper. Biol. \& Med., 1942, 51, 178.

28. Heymann, W., and Startzman, V., Lipemic nephrosis. J. Pediat., 1946, 28, 117.

29. Peters, J. P., and Van Slyke, D. D., Quantitative Clinical Chemistry. Vol. I. Interpretations. Baltimore, Williams and Wilkins Co., 1946.

30. Blumberg, R. W., and Cassady, H. A., Effect of measles on the nephrotic syndrome. Am. J. Dis. Child., 1947, 73, 151.

31. Heymann, W., and Hackel, D. B., The early development of anatomic and blood chemistry changes in the nephrotic syndrome in rats. J. Lab. \& Clin. Med., 1953, 39, 429.

32. Luetscher, J. A., Jr., Electrophoretic analysis of plasma and urinary proteins. J. Clin. Invest., 1940, 19, 313. 
33. Thomas, E. M., Rosenblum, A. H., Lander, H. B., and Fisher, R., Relationships between blood lipid and blood protein levels in the nephrotic syndrome. Am. J. Dis. Child., 1951, 81, 207.

34. Gurin, S., Discussion of paper by Langdon, R. G., Cholesterol metabolism in Fat Metabolism, Report of the Eleventh M. \& R. Pediatric Conference, Columbus, Ohio, M. \& R. Laboratories, 1954, p. 42.

35. Luetscher, J. A., Jr., Piel, C. F., and Curtis, R. H., The nephrotic syndrome. J. Chronic Dis., 1955, 1, 442.

36. Wald, M. H., Clinical studies of secondary amyloidosis in tuberculosis. Ann. Int. Med., 1955, 43, 383.

37. Blainey, J. D., Hardwicke, J., and Whitfield, A. G. W., The nephrotic syndrome associated with thrombosis of the renal veins. Lancet, 1954, 2, 1208.

38. Boggs, T. R., and Morris, R. S., Experimental lipemia in rabbits. J. Exper. Med., 1909, 11, 553.

39. Fishberg, E. H., and Fishberg, A. M., The mechanism of the lipemia of bleeding. Proc. Soc. Exper. Biol. \& Med., 1927, 25, 296.

40. Barker, M. H., and Kirk, E. J., Experimental edema (nephrosis) in dogs in relation to edema of renal origin in patients. Arch. Int. Med., 1930, 45, 319.

41. Kölbl, H., and Peer, E., Hypo- und dysproteinämie bei blutspendern. Klin. Med., 1954, 9, 527.
42. Lewis, L. A., Masson, G. M. C., Corcoran, A. C., and Page, I. H., Effects of renin on serum and urinary proteins in desoxycorticosterone or cortisonetreated rats. Am. J. Physiol., 1955, 180, 331.

43. Zeldis, L. J., Alling, E. L., McCoord, A. B., and Kulka, J. P., Plasma protein metabolism-electrophoretic studies. Chronic depletion of circulating proteins during low protein feeding. J. Exper. Med., 1945, 82, 157.

44. Heymann, W., and Clark, E. C., Pathogenesis of nephrotic hyperlipemia. Am. J. Dis. Child., 1945, 70, 74.

45. Anfinsen, C. B., On the role of lipemia clearing factor in lipid transport in A Symposium on Fat Metabolism, Najjar, V. A., ed., Baltimore, Johns Hopkins Press, 1954, p. 93.

46. Grossman, M. I., Moeller, H. C., and Palm, L., Effect of lipemia and heparin on free fatty acid concentration of serum in humans. Proc. Soc. Exper. Biol. \& Med., 1955, 90, 106.

47. Friedman, M., and Byers, S. O., Role of hyperlipemia in the genesis of hypercholesteremia. Proc. Soc. Exper. Biol. \& Med., 1955, 90, 496.

48. Albrink, M. J., Man, E. B., and Peters, J. P., The relation of neutral fat to lactescence of serum. J. Clin. Invest., 1955, 34, 147.

49. Addis, T., Glomerular Nephritis, Diagnosis and Treatment. New York, The Macmillan Co., 1948. 